\title{
Evaluation on Risk for Ship Collision with Archbridge and Crash Capability of Anti-Collision
}

\author{
Miao Jilun ${ }^{1,2}$, Cai Chuang ${ }^{*}, 2$ and Xiao Shengxie ${ }^{1}$ \\ ${ }^{1}$ School of Civil Engineering and Architecture, Chongqing Jiaotong University, China \\ ${ }^{2}$ Key Laboratory of Hydraulic and Waterway Engineering, Ministry of Education, Chongqing Jiaotong University, \\ China
}

\begin{abstract}
The development of the highway traffic has promoted the construction of increasing numbers of river-crossing bridges, but at the same time, large-size ship causes serious threat to structural safety of the bridge. The probability of bridge-ship collision increases, water safety accidents have happened frequently in the recent years. Arch bridge is easier to be subjected to the threat of ship collision because of small navigation clearance on both sides. However, study on the destructive consequences by ship impact on arch bridge is seldom. This paper takes reinforced concrete arch bridge as an example, on the basis of the forecast of the water-level frequency, flow velocity and long-term navigation density of the ship, the ship collision probability on different parts of the arch ring at different water levels are analyzed to deduce the annual collapse frequency of the grand bridge. The risk matrix evaluation result shows that there is medium risk in longterm. The establishment of finite element numerical model concludes the energy absorption and the change process when the arch ring suffers from collision from the ship under different working conditions as well as the relationship among the impact force, crown displacement and collision depth along with time change. According to the result of simulated analysis, the maximum collision force of the main arch ring suffered from the ship is $25.9 \mathrm{MN}$, and the resistance of the main arch ring is $33.6 \mathrm{MN}$, so the existing structure basically meets the requirement for fortification against the ship collision. The numerical simulation results are qualitatively consistent with the risk of evaluation. The results of the analysis can provide scientific foundation to the maintenance and management of the arch bridge.
\end{abstract}

Keywords: Bridge, Ship Collision, Risk, Load, Resistance.

\section{INTRODUCTION}

With the rapid development of the transportation industry, various types of bridges are built constantly and developed for crossing the inland river to crossing the estuary even crossing the ocean, and the tonnage and speed of the ship is increasing. In the channel with busy transportation, due to the loading capacity of channel greatly exceeding the original designed carrying capacity, the collision accidents between bridge and ship happen frequently to endanger the traffic safety seriously [1]. Statistical data shows that, during 1960-2002, 32 bridges collapsed or serious damage occurred due to the ship collision, globally. There is about one large-scale bridge to be collapsed or damaged seriously due to ship collision every year on average, and the accident brings about huge economic loss and casualties.

Presently, the ship collision problems have been valued all over the world. There are three means for the aspect of study for the ship collision problems such as theoretical calculation analysis, model test and ship test. Minorsky Theory, G. Wosin Collision Theory, Hans-Andrew Cher

*Address correspondence to this author at the School of River \& Ocean Engineering, Chongqing Jiaotong University, Chongqing, 400016 China; Tel: +86 23 68890925; Fax: 023-68812821; E-mail: jimcqcu@ 163.com
Theory and energy exchange principle are based on the quasi-static simulated analysis of collision are the basis of common method to analyze the problem of the pier's collision suffered from the ship [2,3].

In the above common engineering calculation method for bridge and ship collision problems, the factors to be considered are very simple and there is a certain guiding significance for engineering application according to the calculation method derived from empirical data and mainly starting from the impulse formula, energy formula, etc. However, it is increasingly difficult to meet the requirement of engineering construction only by adopting the traditional formula for engineering calculation.

In recent years, with the development of the nonlinear finite element analysis technique and computer hardware system, there is a new breakthrough for the calculation of the ship and bridge collision problems [4]. For different types of ship-bridge collision problems, the complex geometrical shapes, material constitution, failure and damage and other information of ships and bridges can be very accurately described. The more accurate results can be obtained accordingly, and the more traditional empirical equation has embodied the greater superiority [5]. However, most of these focus techniques on the pier or beams, and it seldom pays attention to the damage to the arch ring. The mechanical 
model for ship-bridge collision has been established based on finite element method in this paper to analyze and study the deformation and anti-collision capability of the main arch ring for certain arch bridge under different working conditions.

\section{DESIGN SCHEME FOR BRIDGE STRUCTURE}

\subsection{Bridge Span Arrangement}

Wujiang Bridge in Fuling has been taken as an example. The bridge is the reinforced concrete box arch bridge with $200 \mathrm{~m}$ for main arch span, the rise is $50 \mathrm{~m}$, the full width of bridge deck is $12 \mathrm{~m}$, and the rise span ratio is $1 / 4$. The spandrel building is $15.8 \mathrm{~m}$ reinforced concrete hollow slab simply supported girder bridge with 13 holes and doublecolumn flexible bent frame, and the abutment foundation is placed on the rock, the main arch ring is adopted with box arch form with 3 chambers, and approach bridge is adopted with $31.6 \mathrm{~m}$ simply supported girder bridge, the overall length of the bridge is $352.6 \mathrm{~m}$. As shown in Fig. (1).

\subsection{Structural Type}

\subsubsection{Main Arch Ring}

The main arch ring is the cross section with single box and two chambers. The thickness of the arch ring is $3 \mathrm{~m}$, transversal equivalent width is $8 \mathrm{~m}$, the thickness of the top and bottom plate is $0.4 \mathrm{~m}$, thickness of the plate is $0.45 \mathrm{~m}$. The clear span of the main arch ring is $200 \mathrm{~m}$. Rise span ratio is $1 / 4$. Arch-axis coefficient is 2.328 .

\subsubsection{Spandrel Column}

Two spandrel columns are provided in the transverse direction of the bridge, cross tie beam is provided on the top of column. The width of each column in transverse direction of the bridge is $1.4 \mathrm{~m}$ uniformly. The width along the direction of bridge is $1.2 \mathrm{~m}$ for two groups of accessories at the root of the main arch ring, the dimension of rest is $1 \mathrm{~m}$.

\subsubsection{Prefabricated Hollow Slab}

The span of the hollow slab is $15.8 \mathrm{~m}$. The bridge is provided with 11 hollow slabs, 2 side plates and 9 middle plates.

\subsubsection{Abutment and Boundary Pier}

The abutment is designed as reinforced concrete abutment, and its foundation is placed on the stable and complete weakly-weathered bedrock. The boundary pier is a two-columned pier and the width of the pier in the transverse direction of the bridge is $1.4 \mathrm{~m}$, and $3 \mathrm{~m}$ in the forward direction of the bridge.

\section{SAFTY EVALUATION FOR BRIDGE AND SHIP COLLISION RISK}

\subsection{Parameter Choice}

\subsubsection{Flow Parameter}

The characteristics parameters of water level and water flow rate of the river in bridge area refer to Table $\mathbf{1}$.

Fig. (1). Schematic Diagram for Elevation of Bridge.

Table 1. Flow rate of bridge at different water levels.

\begin{tabular}{|c|c|c|c|c|c|c|}
\hline No. & Water Level (m) & $\begin{array}{c}\text { Annual } \\
\text { Probability of } \\
\text { Occurrence }\end{array}$ & $\begin{array}{c}\text { angle with Flow } \\
\text { Direction( }{ }^{\circ}\end{array}$ & $\begin{array}{c}\text { Longitudinal } \\
\text { Velocity (m/s) }\end{array}$ & $\begin{array}{c}\text { Transverse } \\
\text { Velocity (m/s) }\end{array}$ & $\begin{array}{c}\text { Min. Flow } \\
\text { Rate(m/s) }\end{array}$ \\
\hline \hline 1 & 177.7 & $0.33 \%$ & 6 & 5.97 & 0.63 & 0.23 \\
\hline 2 & 176.0 & $5.67 \%$ & 4 & 3.19 & 0.0 & 0.02 \\
\hline 3 & 173.3 & $50 \%$ & 2 & 0.50 & 0.21 & 3.0 \\
\hline 4 & 164.0 & $18 \%$ & 4 & 2.99 & 0.18 & 2.5 \\
\hline 5 & 159.0 & $11 \%$ & 4 & 2.00 & 0.07 & 2.0 \\
\hline 6
\end{tabular}


While calculating the ship collision risk, upon considering the water level change all the year round, each arch ring unit and the ship collision risk with the whole bridge shall be calculated firstly at different water levels, Then, the weighted sum shall be calculated according to the probability of occurrence at different water levels, namely.

$$
P=\sum_{i=1}^{n} \alpha_{i} P_{w i}
$$

Where, $\alpha_{i}$ is the probability of occurrence of the water level, $P_{w i}$ is the ship collision risk at the water level. The water level in the whole year has been divided into 6 levels.

\subsubsection{Density and Navigational Speed of Navigational Ship}

The navigation density of ship passing through the cross section of the bridge is shown in the Table 2 . The typical navigational speed of the ship can be chosen based on Table 3.

\subsubsection{Other Parameters}

The length of the typical ship is $85 \mathrm{~m}$. The standard value of yaw angle is $0^{\circ}$. The standard deviation of yaw angle is $10^{\circ}$. The accepted risk for annual collapse of the bridge refers to $10^{-4} /$ Year.

\subsection{Results and Analysis on Safety Evaluation for Ship Collision Probability}

Anti-Collision Design Guide Method of Bridge in China and AASHTO Method is adopted to obtain the ship collision probability and the security evaluation result of the main arch ring at different water levels in 2014, 2025 and 2050, listed in Table 4, for details [6, 7]. The results show that the collision risk at arch springing is higher under the influence of flow, clearance height of the ships movement, the collision range of the arch ring at high water level is wider, and the higher the water level, the higher the collision frequency.

It may be observed from the calculation results that, with increase of the year (the navigation capacity is increasing constantly), the annual collision frequency and annual collapse frequency of the main arch ring are increasing constantly. The annual collision frequency and annual collapse frequency of the main arch ring varying with the years are shown in Table 5. The results show that, with the development of navigation business, the ship collision risk of grand bridge is increasing by years. However, until 2050, the ship collision of the main arch ring is still lower than $10^{-4} / \mathrm{Y}$ of accepted risk of important bridge.

Table 2. Forecasted ship navigation capacity at bridge location.

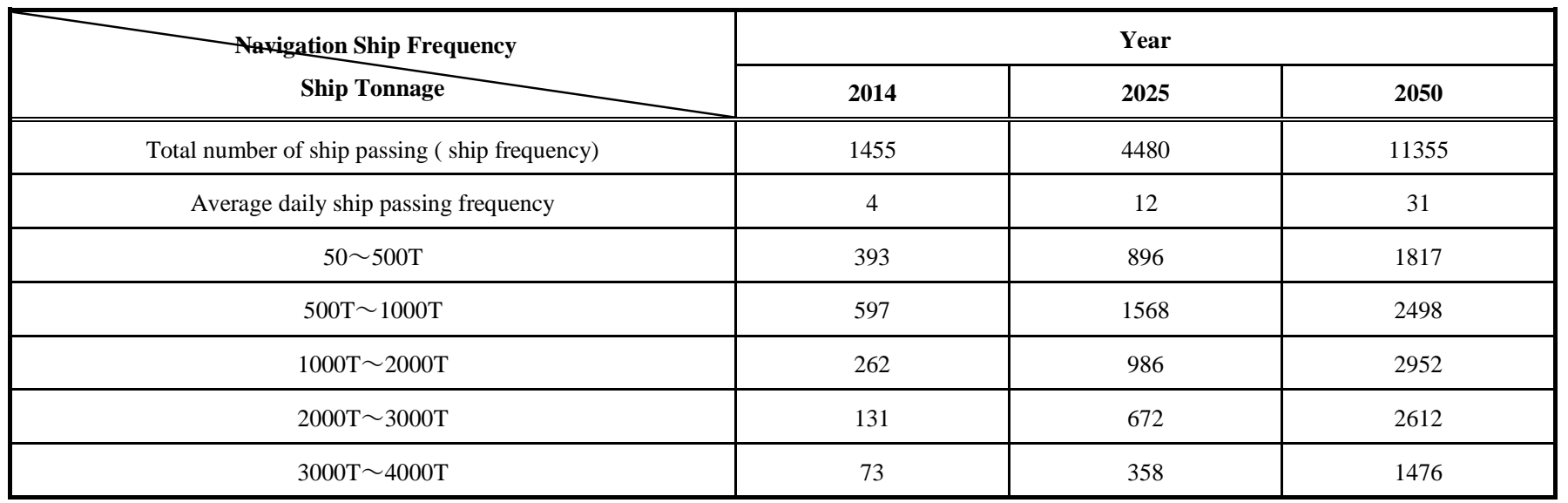

Table 3. Navigational speed of typical ship passing through the bridge.

\begin{tabular}{|c|c|c|}
\hline \multirow{2}{*}{ Ship Tonnage } & \multicolumn{2}{|c|}{ Navigational Speed (m/s) } \\
\cline { 2 - 3 } & Sail Upstream & 5.0 \\
\hline \hline 3000 tonner & 4.0 & 5.0 \\
\hline 2000 tonner & 4.0 & 5.0 \\
\hline 1000 tonner & 4.0 & 5.0 \\
\hline 500 tonner and below & 4.0 & 5.0 \\
\hline Fleet & 4.0 & 5 \\
\hline
\end{tabular}


Table 4. Evaluation results at different water levels in 2014.

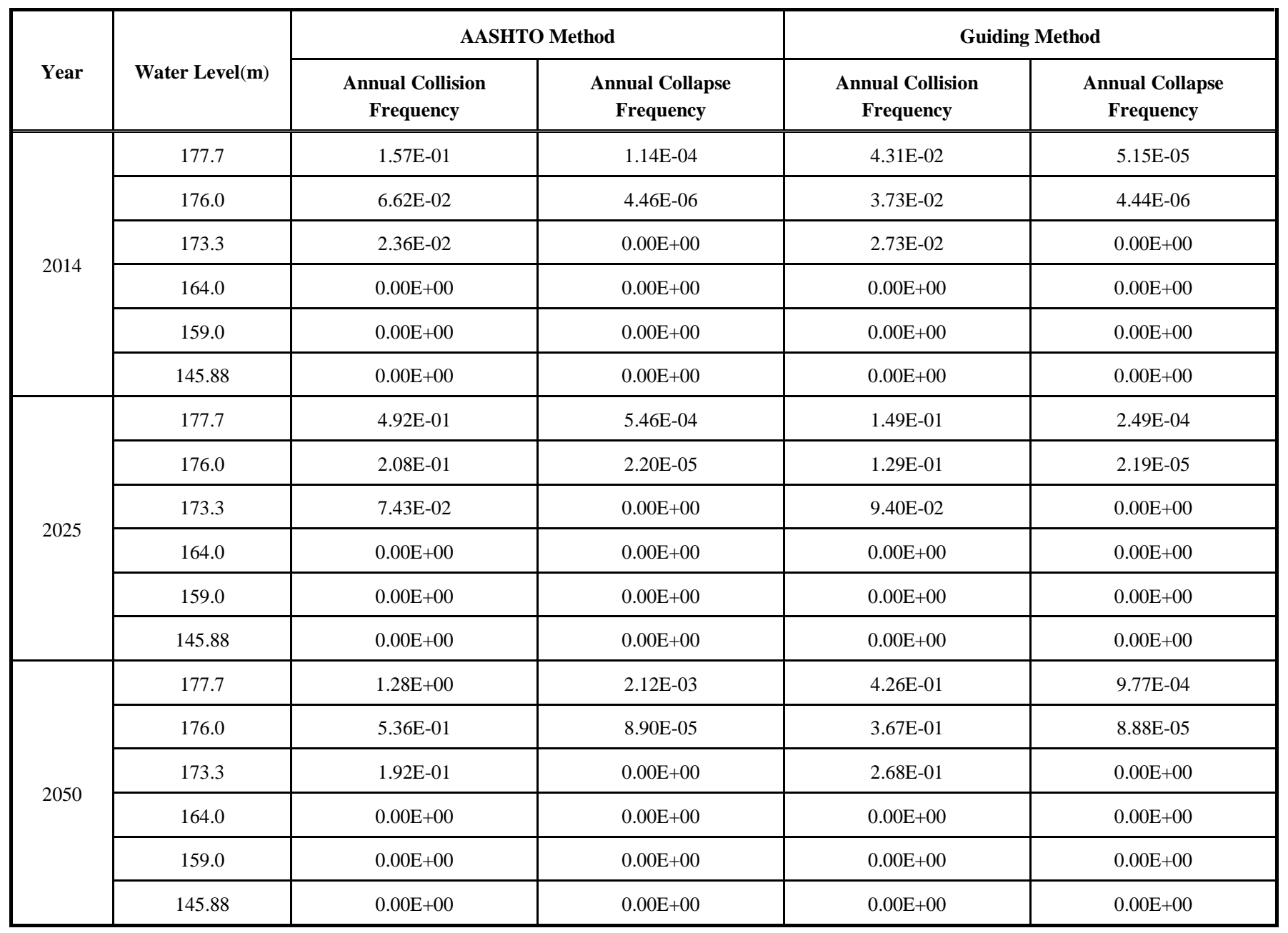

Table 5. Ship collision risk of the main arch ring of bridge.

\begin{tabular}{|c|c|c|c|c|}
\hline \multirow{2}{*}{ Years } & \multicolumn{2}{|c|}{ AASHTO Method } & \multicolumn{2}{c|}{ Guiding Method } \\
\cline { 2 - 5 } & Annual Collision Frequency & Annual Collapse Frequency & Annual Collision Frequency & Annual Collapse Frequency \\
\hline \hline 2014 & $1.61 \mathrm{E}-02$ & $6.28 \mathrm{E}-07$ & $1.59 \mathrm{E}-02$ & $4.22 \mathrm{E}-07$ \\
\hline 2025 & $5.05 \mathrm{E}-02$ & $3.05 \mathrm{E}-06$ & $5.48 \mathrm{E}-02$ & $2.06 \mathrm{E}-06$ \\
\hline 2050 & $1.31 \mathrm{E}-01$ & $1.20 \mathrm{E}-05$ & $1.56 \mathrm{E}-01$ & $8.26 \mathrm{E}-06$ \\
\hline
\end{tabular}

\subsection{Decision on Ship Collision Risk}

\subsubsection{Risk Level and Risk Assessment Matrix}

In order to determine the position of various risks of collision between bridge and ship in assessment matrix, based on relevant study and combined with the characteristics of collision risks between bridge and ship, the level grading on risk probability of ship collision is obtained as shown in Table 6.

Meanwhile, according to the damage degree, economic loss and social collision of structure and combining the specific characteristics of collision risk between bridge and ship, the decided level grade of ship collision risk consequences refers to Table 7 .
In combination with the above level grade of risk probability and level grade of risk consequence, risk assessment matrix and decision criteria applied in this paper respectively refer to Table $\mathbf{8}$ and Table $\mathbf{9}$.

\subsubsection{Grade Evaluation Result and Decision}

According to the previous risk analysis results and grade evaluation method, the determined risk grade of grand bridge refers to Table $\mathbf{1 0 .}$

It can be known from above description that, although the value of yearly collapsed frequency for bridge calculated by ASSHTO method and Guide method is different, the result of grade evaluation is basically consistent. According 
Table 6. Grading on risk probability of collision between bridge-ship.

\begin{tabular}{|c|c|c|c|c|c|c|}
\hline Grade & A & B & C & D & E & F \\
\hline \hline Qualitative Description & Impossible & Rare & Scarce & Occasional & Possible & Frequent \\
\hline Probability Description & $10^{-6}$ & $10^{-4} \sim 10^{-6}$ & $10^{-3} \sim 10^{-4}$ & $10^{-2} \sim 10^{-3}$ & $10^{-1} \sim 10^{-2}$ & $>10^{-1}$ \\
\hline
\end{tabular}

Table 7. Grade of consequences of collision risk between bridge- ship.

\begin{tabular}{|c|c|c|c|c|c|}
\hline Grade & $\mathbf{1}$ & $\mathbf{2}$ & $\mathbf{3}$ & $\mathbf{5}$ \\
\hline \hline $\begin{array}{c}\text { Qualitative Description } \\
\text { Structure }\end{array}$ & Negligible & Smaller & Medium & Severe \\
\hline $\begin{array}{c}\text { Mo Damage or } \\
\text { Economic Loss }\end{array}$ & Smaller Economic Loss & Medium Economic Loss & Higher Economic Loss & Serious Economic Loss & Huge Economic Loss \\
\hline Social Collision & Slight Social Collision & Low Social Collision & Medium Social Collision & Grandr Social Collision & Bad Social Collision \\
\hline
\end{tabular}

Table 8. Risk assessment matrix of collision risk between bridge and ship.

\begin{tabular}{|c|c|c|c|c|c|}
\hline Risk Consequence & $\begin{array}{c}\mathbf{1} \\
\text { Regligible }\end{array}$ & $\begin{array}{c}\mathbf{2} \\
\text { Smaller }\end{array}$ & $\begin{array}{c}\mathbf{3} \\
\text { Medium }\end{array}$ & $\begin{array}{c}\mathbf{4} \\
\text { Severe }\end{array}$ & $\begin{array}{c}\mathbf{5} \\
\text { Catastrophic }\end{array}$ \\
\hline \hline $\mathrm{A}\left(10^{-6}>\mathrm{X}\right)$ & $1 \mathrm{~A}$ & $2 \mathrm{~A}$ & $3 \mathrm{~A}$ & $4 \mathrm{~A}$ & $5 \mathrm{~A}$ \\
\hline $\mathrm{B}\left(10^{-4}>\mathrm{X}>10^{-6}\right)$ & $1 \mathrm{~B}$ & $2 \mathrm{~B}$ & $3 \mathrm{~B}$ & $4 \mathrm{C}$ & $5 \mathrm{~B}$ \\
\hline $\mathrm{C}\left(10^{-3}>\mathrm{X}>10^{-4}\right)$ & $1 \mathrm{C}$ & $2 \mathrm{C}$ & $3 \mathrm{C}$ & $3 \mathrm{D}$ & $5 \mathrm{D}$ \\
\hline $\mathrm{D}\left(10^{-2}>\mathrm{X}>10^{-3}\right)$ & $1 \mathrm{D}$ & $2 \mathrm{D}$ & $3 \mathrm{E}$ & $4 \mathrm{E}$ & $5 \mathrm{E}$ \\
\hline $\mathrm{E}\left(10^{-1}>\mathrm{X}>10^{-2}\right)$ & $1 \mathrm{E}$ & $2 \mathrm{E}$ & $2 \mathrm{~F}$ & $4 \mathrm{~F}$ & $5 \mathrm{~F}$ \\
\hline $\mathrm{F}\left(\mathrm{X}>10^{-1}\right)$ & $1 \mathrm{~F}$ & & 2 & 5 \\
\hline
\end{tabular}

Table 9. Decision criteria for bridge risk.

\begin{tabular}{|c|c|c|}
\hline Risk Grade & Region & Countermeasures for Risk Disposal \\
\hline \hline Negligible & $1 \mathrm{~A}, 2 \mathrm{~A}, 1 \mathrm{~B}$ & Acceptable,management and review are unnecessary. \\
\hline Low risk & $3 \mathrm{~A}, 2 \mathrm{~B}, 3 \mathrm{~B}, 1 \mathrm{C}, 2 \mathrm{C}, 1 \mathrm{D}, 4 \mathrm{~A}$ & Acceptable, management shall be reinforced during the whole process of construction and operation. \\
\hline Medium risk & $5 \mathrm{~A}, 4 \mathrm{~B}, 3 \mathrm{C}, 2 \mathrm{D}, 1 \mathrm{E}, 1 \mathrm{~F}$ & Conditional acceptable, had better further reduce the risk \\
\hline High risk & $5 \mathrm{~B}, 4 \mathrm{C}, 5 \mathrm{C}, 3 \mathrm{D}, 4 \mathrm{D}, 2 \mathrm{E}, 3 \mathrm{E}, 2 \mathrm{~F}$ & Undesirable, senior management must make decision to reduce risk \\
\hline Extremely high risk & $5 \mathrm{D}, 4 \mathrm{E}, 5 \mathrm{E}, 3 \mathrm{~F}, 4 \mathrm{~F}, 5 \mathrm{~F}$ & Unacceptable,stop operation and reorganize promptly \\
\hline
\end{tabular}

to the result assessed by AASHTO method and Guide method, arch ring of the grand bridge is in a low risk condition, and the risk grade may be up to medium risk condition with the development of shipping business, the management shall be reinforced during the operating process of the grand bridge.

\section{NUMERICAL SIMULATION ON COLLISION BETWEEN GRAND BRIDGE AND SHIP}

\subsection{Finite Element Model}

Dynamic numerical simulation method is applied for the calculation of the collision function to bridge from the ship. LS-DYNA based on explicit algorithm is applied for the 
Table 10. Risk Grade of collision between bridge and ship.

\begin{tabular}{|c|c|c|c|c|c|c|}
\hline Method & \multicolumn{2}{|c|}{2014} & \multicolumn{2}{|c|}{2025} & \multicolumn{2}{|c|}{2050} \\
\hline Guiding & $6.28 \mathrm{E}-07$ & $\begin{array}{c}4 \mathrm{~A} \\
\text { Low Risk }\end{array}$ & $3.05 \mathrm{E}-06$ & $\begin{array}{c}\text { 4B } \\
\text { Med. Risk }\end{array}$ & $1.20 \mathrm{E}-05$ & $\begin{array}{c}\text { 4B } \\
\text { Med. Risk }\end{array}$ \\
\hline AASHTO & 4.22E-07 & $\begin{array}{c}\text { 4A } \\
\text { Low Risk }\end{array}$ & $2.06 \mathrm{E}-06$ & $\begin{array}{c}\text { 4B } \\
\text { Med. Risk }\end{array}$ & $8.26 \mathrm{E}-06$ & $\begin{array}{c}\text { 4B } \\
\text { Med. Risk }\end{array}$ \\
\hline
\end{tabular}

analysis software. Collision function between collision structures is completed by contact algorithm. Principal and subordinate contact surface are respectively defined on the two collided objects, in every time step of calculation. The acting force, whether to be acted on the principal surface, depends on the subordinate node, whether to penetrate the principal surface, and this force is the contact force. The grade of contact force depends on the penetrating quantity and element characteristics on both sides of contact the surface $[8,9]$.

There are many factors affecting the accuracy of the computed result, such as, friction between materials, selection of calculation element, and control of hourglass. Especially the function of element types and elaborate degree of grid, and the strain rate of materials also has a great affect function $[10,11]$. Concrete material in the calculation of numerical simulation shall be adopted with elastic material conservatively and elastic constitutive relation, and the density of the cement is $2500 \mathrm{~kg} / \mathrm{m}^{3}$, Poisson's ratio is 0.17 . Entity unit is applied for the arch ring part of the model, and beam element is adopted for bridge on the arch and deck. In order to shorten the calculation time, other parts without direct contact with ship shall be divided by entity unit with larger size. Numerical simulation of ship collision shall be adopted with 2000DWT bulk cargo ship, calculation model of arch bridge refers to Fig. (2), and grid model of ship refers to Fig. (3).

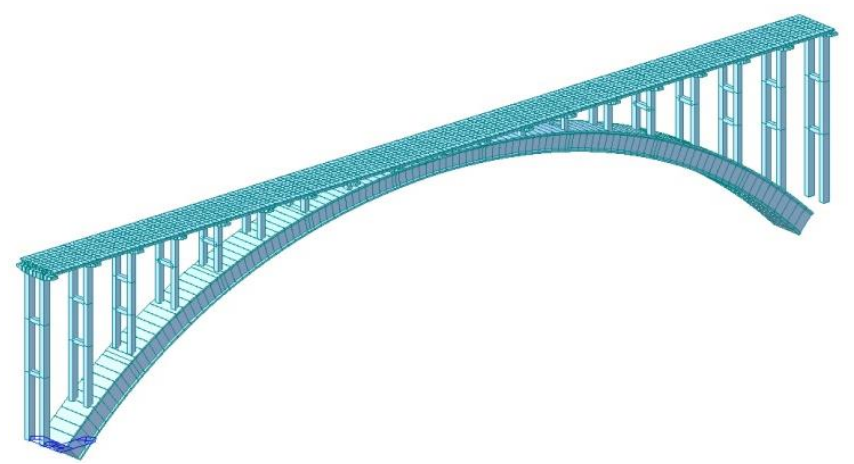

Fig. (2). Calculation Model of Arch Ring Resistance for Main Bridge.

\subsection{Calculation of Arch Ring Resistance for Main Bridge}

Main arch ring model shall be built as actual condition for the calculation of ship collision resistance of bridge's arch ring. The upper structure and columns shall be adopted with node load simulation by considering the influence of self weight, load combination of the calculation of ship collision resistance includes dead load, automobile, crowd and ship collision force.

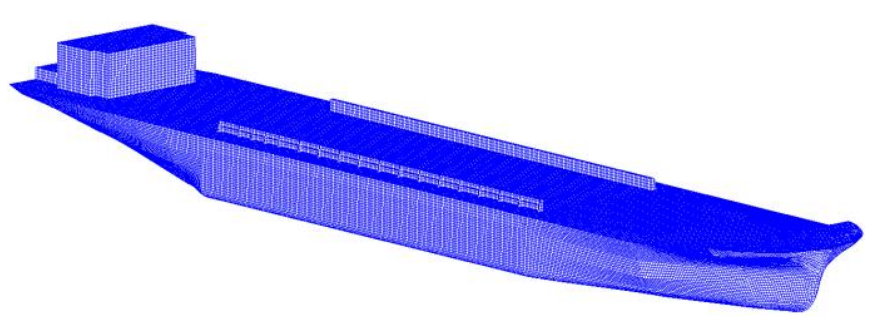

Fig.(3). Finite Element Calculation Model of 2000t Ship.

Maximum internal force of bridge's main arch ring under the function of transverse collision force in various heights shall be calculated and analyzed by the finite element method, and then, the compression resistance and loading capability of the normal section of the dangerous section shall be calculated by eccentric compression members to know ship collision resistance of the bridge's arch ring. If the horizontal force is acted on the different points, the limited ship collision resistance of arch ring is also different. Section of arch bridge refers to Fig. (4). According to the reinforcement conditions of the arch ring section, horizontal force with various strengths shall be imposed in the same water level, until the arch ring risk section dissatisfies strength requirements, and this horizontal force is the extreme ship collision force of arch ring under this water level.

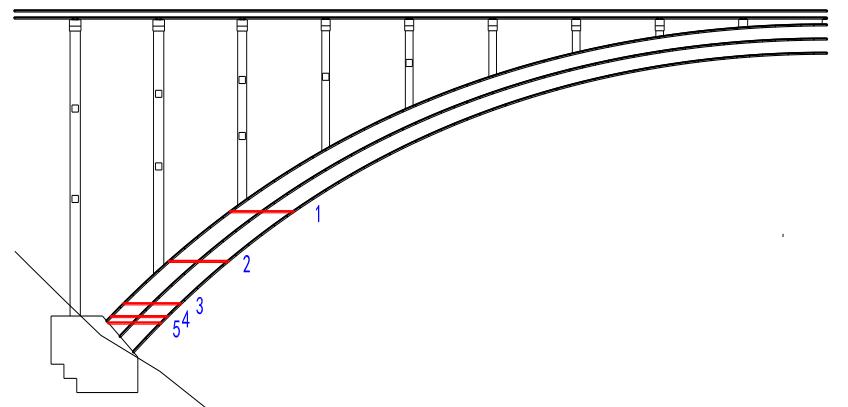

Fig.(4). Calculation Schematic Diagram of Arch Ring Self Limit Ship Collision Force.

Calculation result of self limit ship collision force of the main arch ring is shown in Table 11. Therein, $192.7 \mathrm{~m}$ on point No.1 is added with $15 \mathrm{~m}$ based on the maximum 
Table 11. Self limit ship collision force of arch ring (Transverse Direction of Bridge).

\begin{tabular}{|c|c|c|c|c|c|}
\hline No. & Elevation of Collision Point $(\mathbf{m})$ & Position & \multicolumn{2}{|c|}{ Internal Force } & Resistance $(\mathbf{K N})$ \\
\hline 2 & 185.7 & Arch ring & -132948 & 373820 & 14400 \\
\hline 3 & 179.7 & Arch ring & -132948 & 372800 & 33600 \\
\hline 5 & 175.3 & Arch ring & -132948 & 373570 & 60000 \\
\hline
\end{tabular}

navigable water level $(177.7 \mathrm{~m})$, resistance result is used for review collision conditions of mast. $185.7 \mathrm{~m}$ on point No. 2 is added with $8 \mathrm{~m}$ based on the maximum navigable water level $(177.7 \mathrm{~m})$, the resistance result is used for checking the collision conditions of deck house, point No.3 5 elevation is corresponding to the stem collision point according to three water levels where the stem can collide with the arch ring $(177.7 \mathrm{~m}, 176 \mathrm{~m}$ and $173.3 \mathrm{~m})$, i.e. $2 \mathrm{~m}$ above navigable water level.

\subsection{Calculation Result of Dynamic Numerical Simulation}

The maximum collision force of structure shall be simulated and calculated by different water levels, different collision positions, different speeds and collision angles in 6 operating conditions. Calculation of operating conditions refers to Table $\mathbf{1 2 .}$

Energy change process, collision force, crown displacement, and change collision depth with the change of time are acquired by calculation in various operating conditions. Take working condition 1 as example, when the navigable water level is $177.7 \mathrm{~m}$, cargo ship in $2000 \mathrm{t}$ collision arch ring with the speed of $4.9 \mathrm{~m} / \mathrm{s}$, collision angle is $0^{\circ}$ with normal of the bridge. Energy conversion in the process of collision shall refer to Fig. (5). The kinetic energy, internal energy, and sliding energy produce the mutual transformation in the process of collision, but the total energy is stable and hourglass is in good control.
Changing condition of collision force of the ship is shown in Fig. (6), the maximum value of ship collision force is $25.9 \mathrm{MN}$ after $0.61 \mathrm{~s}$ of the collision. Time-history for crown displacement refers to Fig. (7), the maximum value of crown displacement is $2.72 \mathrm{~mm}$ after $1.25 \mathrm{~s}$ of the collision. Changing situations for collision depth of the ship is shown on Fig. (8), the maximum value of ship collision depth is $1.82 \mathrm{~m}$ after $1.1 \mathrm{~s}$ of the collision, the maximum value of main stress is $5.4 \mathrm{MPa}$. Calculation results of various operating conditions are shown in Table $\mathbf{1 2 .}$

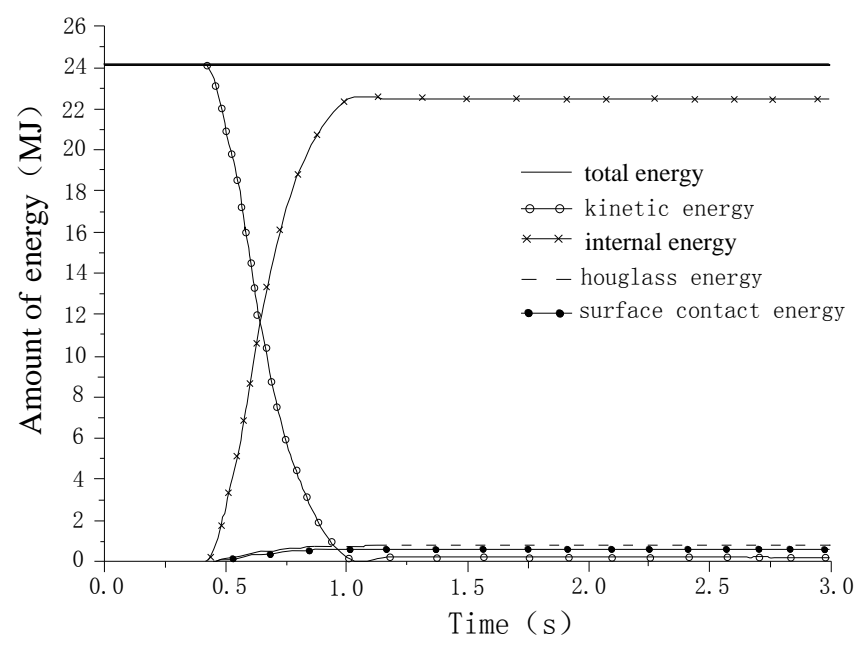

Fig. (5). Energy Time-History for Collision Process.

Table 12. Calculation result of various working conditions.

\begin{tabular}{|c|c|c|c|c|c|c|c|c|}
\hline No. & $\begin{array}{c}\text { Water } \\
\text { Level(m) }\end{array}$ & $\begin{array}{c}\text { Collision } \\
\text { Position }\end{array}$ & $\begin{array}{c}\text { Collision } \\
\text { Angle }\left(^{(}\right)\end{array}$ & $\begin{array}{c}\text { Collision } \\
\text { Speed(m/s) }\end{array}$ & $\begin{array}{c}\text { Collision } \\
\text { Force(MN) }\end{array}$ & $\begin{array}{c}\text { Crown } \\
\text { Displacement } \\
(\mathbf{m m})\end{array}$ & $\begin{array}{c}\text { Collision } \\
\text { Crater } \\
\text { Depth (m) }\end{array}$ & $\begin{array}{c}\text { Resistance } \\
\text { Capacity(MN) }\end{array}$ \\
\hline \hline 1 & 177.7 & Nose & $0^{\circ}$ & 4.9 & 25.9 & 2.72 & 1.82 & 33.6 \\
\hline 2 & 177.7 & Nose & $30^{\circ}$ & 4.9 & 18.0 & 2.03 & 1.25 & 33.6 \\
\hline 3 & 177.7 & Deck house & $0^{\circ}$ & 4.9 & 5.0 & 1.7 & 1.0 & 14.4 \\
\hline 4 & 177.7 & Mast & $0^{\circ}$ & 4.9 & 0.85 & 0.5 & - \\
\hline 5 & 173.3 & Deck house & $0^{\circ}$ & 4.8 & 3.8 & 0.3 & 0.4 & 18.9 \\
\hline 6 & 173.3 & Mast & $0^{\circ}$ & 4.8 & 0.92 & 0.2 & - & 8.78 \\
\hline
\end{tabular}




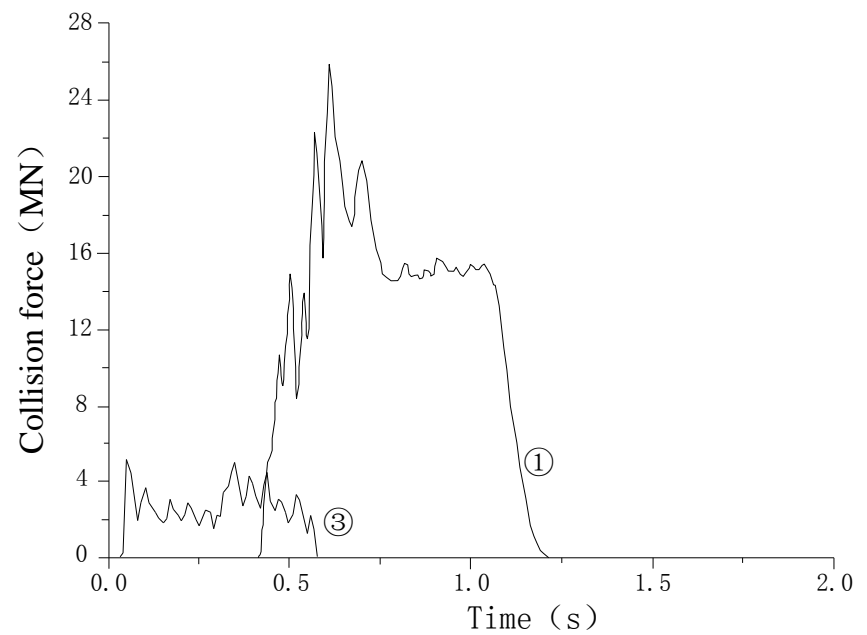

Fig.(6). Time-History for Ship Collision Force.

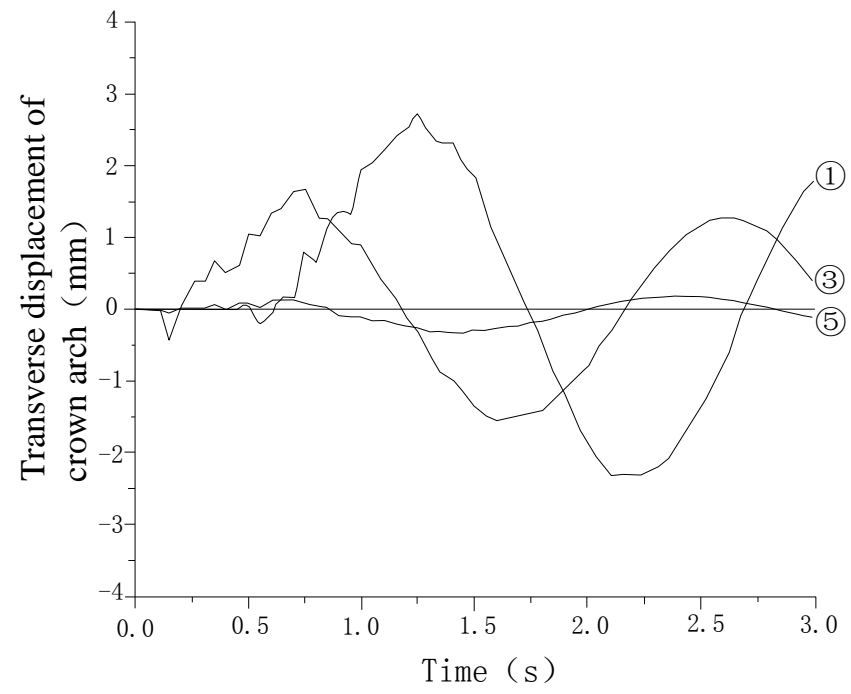

Fig.(7). Time-History for Crown Displacement.

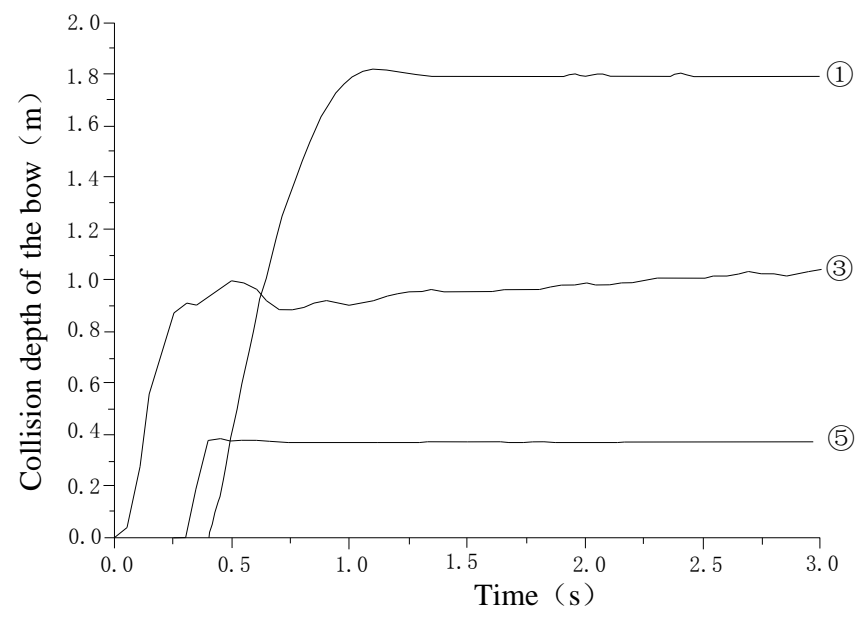

Fig.(8). Time-History for Collision Depth Change.

\section{CONCLUSION}

Yearly collapse frequency of main arch ring under the predictive navigation density in 2014, 2025 and 2050 is $6.28 \times 10^{-7} /$ year, $3.05 \times 10^{-6} /$ year, $1.20 \times 10^{-5} /$ year, respectively, based on the assessment results of ship collision risk method. These results are all less than the acceptable risk $10^{-4} /$ year of main bridge. Main arch ring of bridge is in medium risk under the predictive navigation density in 2050 and shall be adopted with self resistance. Ship collision force on the main arch ring is $25.9 \mathrm{MN}$ (corresponding water level is $177.7 \mathrm{~m}$ ), and resistance of main arch ring in this water level is $33.6 \mathrm{MN}$, so the existing structure meets the requirement of ship collision fortification. Numerical simulation results are consistent with risk assessment qualitatively. In order to ensure the safety of bridge and ship navigation, ships on the bridge section shall be suggested for sailing in separate ways. Ship meeting, combination and surpassing are prohibited around the bridge location.

Collision between ship and bridge is a typical multidisciplinary crossing question, involving bridge construction, ship engineering, traffic engineering, collision dynamics and hydromechanics etc. This paper provided a way to evaluate the risk for ship collision with Arch-bridge. The safety assessment of ship risks and dynamic numerical simulation method applied in this article shall be referred and used for the ship anti-collision analysis of similar bridges.

\section{CONFLICT OF INTEREST}

The authors confirm that this article content has no conflict of interest.

\section{ACKNOWLEDGEMENTS}

This research was supported by China Postdoctoral Science Foundation(Grant No. 2014M552538XB), Chongqing science \& technology commission fund(Grant No. cstc2014jcyjA30021), the open fund of national engineering technology research center for inland waterway regulation, and Key laboratory of hydraulic and waterway engineering, ministry of Education, Chongqing Jiaotong University(Grant No. SLK2014B04).

\section{REFERENCES}

[1] J. Wu, "Development of ship-bridge collision analysis", $J$. Guangdong Commun. Polytech., vol. 4, pp. 60-64, 2004.

[2] H. Lenselink, K.G. Thung, "Numerical simulation of ship collisions", In: Proceedings of the Second International of Shore and Polar Engineering Conference, 1992, pp. 40-46.

[3] L.J. Wevers, A.W.Vredeveldt, "Full scale ship collision tests", Third International Symposium on Structural Crash Worthiness and Failure, 1993, pp. 145-150.

[4] J. Wang, H. Yan, H. Qian, "Comparisons of design formula of ship collision for bridges based on FEM simulation", J. Highway Transport. Res. Dev., vol. 23, no. 2, pp. 68-73, 2006.

[5] J. Wang, D. Meng, B. Ou, "Basic impact loading models for head bow-on collision between a ship and a rigid wall", J. Vib. Shock, vol. 29, no. 11, pp. 165-170, 2010.

[6] AASHTO. "LRFD bridge design specification and commentary", American association of state highway and transportation officials, Washington D. C, 2004, pp. 253-257.

[7] AASHTO, "Guide specification and commentary for vessel collision design of highway bridges", 2009, pp. 341-344.

[8] G.R.Consolazio, D.R.Cowan, "Nonlinear analysis of barge crush behavior and its relationship to impact resistant bridge design", Comput. Struct., vol. 81, pp. 547-557, 2003.

[9] P. T. Petersen, S. Zhang, "On impact mechanics in ship collision", Marine Struct., vo1. 1, no. 10, pp. 42-49, 1998. 
[10] C. Guo-yu, "New equipment of ship collision with the pier and its mechanism research", Ship Eng., vol, 29, no. 4, pp. 40-43, 2007.
[11] G. Huang, X. Lan, "Compare of pier impact force in the three kinds of norms", Transport. Sci. Tech., vol. 249, no. 6, pp. 14-16, 2011.

Received: September 22, 2014

Revised: November 30, 2014

Accepted: December 02, 2014

(C) Jilun et al.; Licensee Bentham Open.

This is an open access article licensed under the terms of the Creative Commons Attribution Non-Commercial License (http://creativecommons.org/licenses/by-nc/3.0/) which permits unrestricted, non-commercial use, distribution and reproduction in any medium, provided the work is properly cited. 